\title{
Clinical assessment and radiograph following blunt chest trauma
}

\author{
M. G. DUNLOP, T. F. BEATTIE, P. G. PRESTON \& \\ D. J. STEEDMAN \\ Department of Accident and Emergency Medicine, Royal Infirmary, Edinburgh, Scotland
}

\section{SUMMARY}

This study was undertaken to assess the accuracy of clinical examination in predicting significant injury following blunt chest trauma and to determine whether more selective use of frontal chest radiography could be achieved.

\section{INTRODUCTION}

Chest radiography following blunt chest trauma is routine practice in accident and emergency departments. X-ray examination is only required to demonstrate multiple rib fractures or complications (Kattan, 1980). Oblique views do not influence management and are therefore unnecessary, (De Luca et al., 1982; Danher et al., 1984). Frontal radiography also warrants re-appraisal.

\section{PATIENTS, METHODS AND RESULTS}

Over a 3-month period, 241 consecutive patients presenting with blunt chest trauma were studied prospectively. Prior to frontal chest radiography, the following details were recorded in a pro forma; age, sex, mechanism of injury, visible evidence of injury, localized or diffuse tenderness, the presence of rib crepitus, surgical emphysema, abnormal percussion or auscultation. The clinician's subjective prediction of fracture or complication was noted. Each radiograph was evaluated by a radiologist with no access to clinical data. The value of each parameter in predicting significant injury (that is, multiple rib fractures and/or complications) was analysed and statistical significance assessed by Fisher's Exact Test.

There were 170 males and 71 females aged 15-86 years (mean 52 years). The mechanism of injury ranged from simple falls to road-traffic accidents.

Correspondence: Mr M. G. Dunlop, MRC Human Genetics Unit, Western General Hospital, Crewe Road, Edinburgh EH4 $2 X U$, Scotland. 
Twenty-nine patients sustained rib fractures, eight of whom had three or more fractures. One patient had a fractured clavicle and another an isolated fracture of T9.

There were 18 intrathoracic complications: six pneumothoraces; four pleural effusion/haemothorax; two pulmonary contusions and six collapse/consolidations. Eleven of these were associated with rib fracture, six of whom had sustained three or more fractures. The patient with a clavicular fracture had a pneumothorax.

Patients with multiple rib fractures were significantly more likely to have an associated complication $(P=0.036)$. Correlation of clinical assessment with injury (Table 1$)$ demonstrated that rib crepitus $(P<0.0001)$, surgical emphysema $(P=0.04)$ or abnormal auscultation $(P<0.006)$ were significant in predicting multiple fractures and/ or complications. However, the overall sensitivity for a positive finding with any one, or any combination, of these parameters was low (50\%) and therefore exclusion of serious injury based on these features was impossible. The clinicans subjective assessment was also unreliable. Although multiple rib fractures were all correctly diagnosed, only $45 \%$ of complications were suspected.

Table 1 Clinical assessment and injury sustained*

\begin{tabular}{|c|c|c|c|c|c|}
\hline & \multicolumn{2}{|c|}{ Fracture } & \multicolumn{3}{|c|}{ No fracture } \\
\hline & $\begin{array}{l}\text { Complication } \\
\quad(n=12)\end{array}$ & $\begin{array}{l}\text { No complication } \\
\qquad(n=19)\end{array}$ & $\begin{array}{l}\text { Complication } \\
\qquad(n=6)\end{array}$ & $\begin{array}{l}\text { No complicatior } \\
(n=204)\end{array}$ & n \\
\hline Visible mark & 4 & 4 & 1 & 43 & రृ \\
\hline \multicolumn{6}{|l|}{ Tenderness: } \\
\hline localized & 10 & 15 & 2 & 165 & $\stackrel{?}{?}$ \\
\hline diffuse & 2 & 4 & 4 & 39 & \\
\hline Rib crepitus & 5 & 2 & 2 & 6 & \\
\hline Surgical emphysema & 2 & 1 & 0 & 0 & \\
\hline Abnormal percussion & 1 & 0 & 0 & 2 & \\
\hline Abnormal auscultation & 4 & 2 & 1 & 7 & \\
\hline
\end{tabular}

* The majority of fractures were of the ribs but also include one fracture of the clavicle and one fracture of the ninth vertebral body.

\section{COMMENT}

Clinicians (Warren \& Ferguson, 1984) and radiologists (de Lacey et al., 1979) agree that casualty officers frequently request unnecessary X-rays. However, this study has highlighted the inadequacies of clinical assessment in predicting significant injury $N$ following blunt chest trauma. Although rib crepitus, surgical emphysema and abnormal $N$ auscultation predict that serious injury is likely, selective guidelines for frontal radiography based on these parameters are unacceptable as a significant proportion of 0 serious injuries would be missed. Clinical assessment alone is therefore insufficient. We $\varrho$ recommend that every patient undergoes frontal chest radiography in addition to careful clinical examination, thereby allowing multiple rib fractures and complications to be recognized and appropriate management initiated. 


\section{REFERENCES}

Danher J., Eyes B. E. \& Kumbar K. (1984) Olique rib views after blunt chest trauma; an unnecessary routine? British Medical fournal 289, 1271.

de Lacey G., Barker A. \& Wignall B. (1979) Reason for requesting radiographs in an accident department. British Medical fournal 1, 1595.-97

De Luca S. A., Rhea J. T. \& O'Malley T. (1982) Radiographic evaluation of rib fractures. American fournal of Roentgenology 138, 91-92.

Kattan K. R. (1980) What to look for in rib fractures and how. Fournal of the American Medical Association 243, $262-4$.

Warren R. A. \& Ferguson D. G. (1984) Why do accident and emergency doctors request X-rays? Archives of Emergency Medicine 3, 143-50. 